\title{
Digital tools for marine activities sustainable development under climate change and COVID- 19
}

\author{
Valery Abramov*, Vyacheslav Burlov, Yaroslav Petrov, Igor Sikarev, and Oleg Shevchuk \\ Russian State Hydrometeorological University, Voronezhskaya str., 79, 192007 St.-Petersburg, \\ Russia
}

\begin{abstract}
There are presented digital tool development results for the sustainable development of marine activities adapted to climate change and COVID-19 conditions. Arctic and Subarctic are selected as main area of sustainable development of marine activities. Digitalization of geoinformation support for the sustainable development of marine activities is main direction of the research. Aim of the study is to create digital tools of geoinformation support for sustainable development of marine activities, taking into account the above factors. It is proposed to use open-source geoinformation online platforms while the sustainable development of marine activities in the Arctic and Subarctic in the period of Industry 4.0 in the context of climate change and COVID-19. Examples of the use of the proposed digital platforms are considered. The results of the research can be used for educational purposes, as well as be useful for private investors, state and municipal organizations.
\end{abstract}

\section{Introduction}

Currently, a lot of innovative information technologies are implemented within the framework of geoinformation management (GIM) [1-5]. This leads to significant changes in the geoinformation support for sustainable development of marine activities (SDMA), especially in the Arctic and Subarctic, which should be implemented in the Industry 4.0 era, when climate change and the COVID-19 pandemic are simultaneously occurring. It should be noted that Industry 4.0 leads to major technological changes in the geoinformation support systems (GISS) and management support systems (MSS) for SDMA, especially in the Arctic and Subarctic, including the geo-ecological support systems (GESS) [6-13] and natural risk management (NRM) [14-17], which requires the development of new digital technologies and tools. Within the framework of the SDMA, special attention should be paid to environmental safety (ES) [18-23] and compensatory measures (CM) [24-27].

The purpose of this article is the digitalization of the GESS for the NRM, ES and CM within the framework of the SDMA, especially in the Arctic and Subarctic. The article describes the results of the development of innovative digital tools NRM, ES and CM within the framework of the SDMA, especially in the Arctic and Subarctic, within the GIM

${ }^{*}$ Corresponding author: val.abramov@mail.ru 
paradigm, including the issues of information collection and processing [28-30] in the context of climate change and the COVID-19 pandemic.

\section{Materials and methods}

In research, we used Foresight technologies, risk management approach, theory of decision making under uncertainties, Foresight technologies, methods of data bases constructing and web-technologies. Also, it is used big data technologies [28-30]. From the point of view of GIM, geo-space structured to allocate the interconnected components of the solution space [4]. In research, it is used data bases and tools of geo-information digital online platforms (GIDOPs) VesselFinder https://www.vesselfinder.com/ and EOS, including its Land Viewer (LV) product https://eos.com/landviewer/.

\section{Results}

As a result of the study, it is argued that the marine activity digital transformation, especially in the Arctic and Subarctic, at the present stage should be implemented in the paradigm of sustainable development as an interconnected set of large natural and industrial projects (PIP) within a single space-time space and a single adequate geoinformation and management support. Based on research using Foresight technologies, it is proposed to develop a GESS and a MSS for SDMA, especially in the Arctic and Subarctic, with a combined structure for accessing, storing and analyzing information from open geospatial data sources, including archives and web-based operational tools. It is proposed to use the geoinformation distributed online platforms (GIDOPs) VesselFinder https://www.vesselfinder.com/ and EOS, including its Land Viewer (LV) product https://eos.com/landviewer/ as the main technological solutions to GISS and a MSS for SDMA, especially in the Arctic and Subarctic.

In fig.1-3, we present examples of above mentioned GIDOPs using.

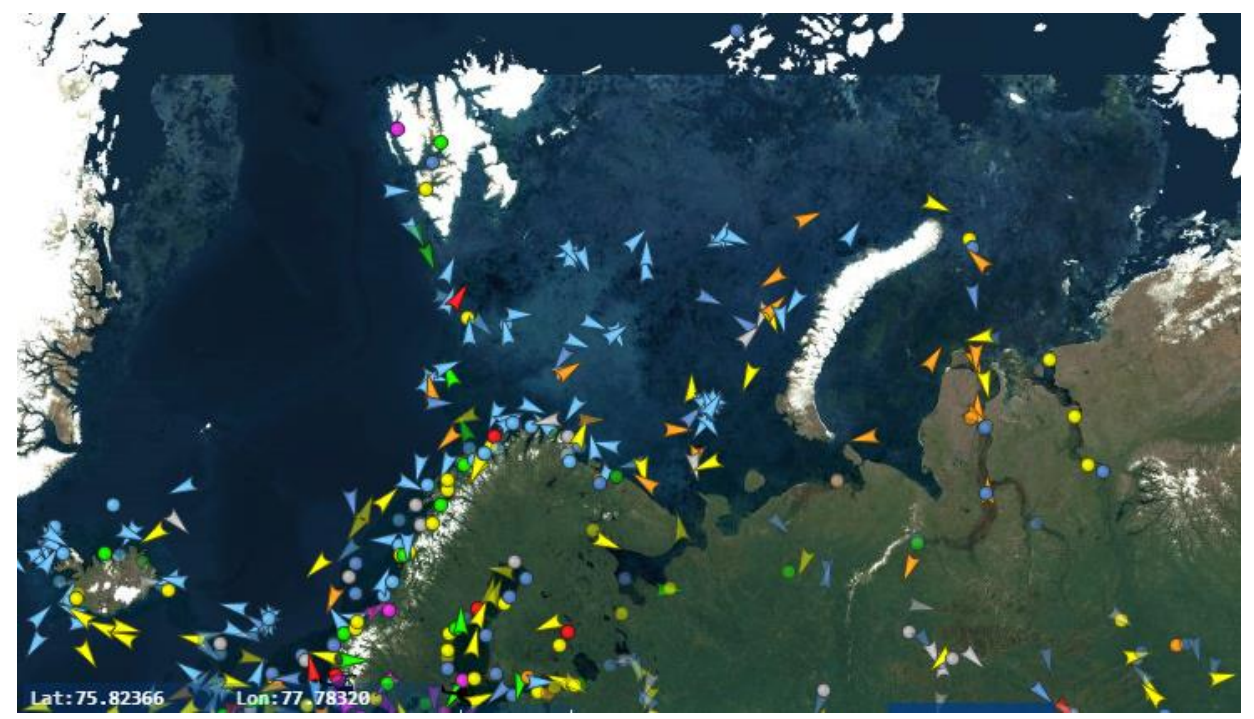

Fig. 1. Visualization of ship traffic in Arctic waters using Vessel Finder on 23/05/2021. 


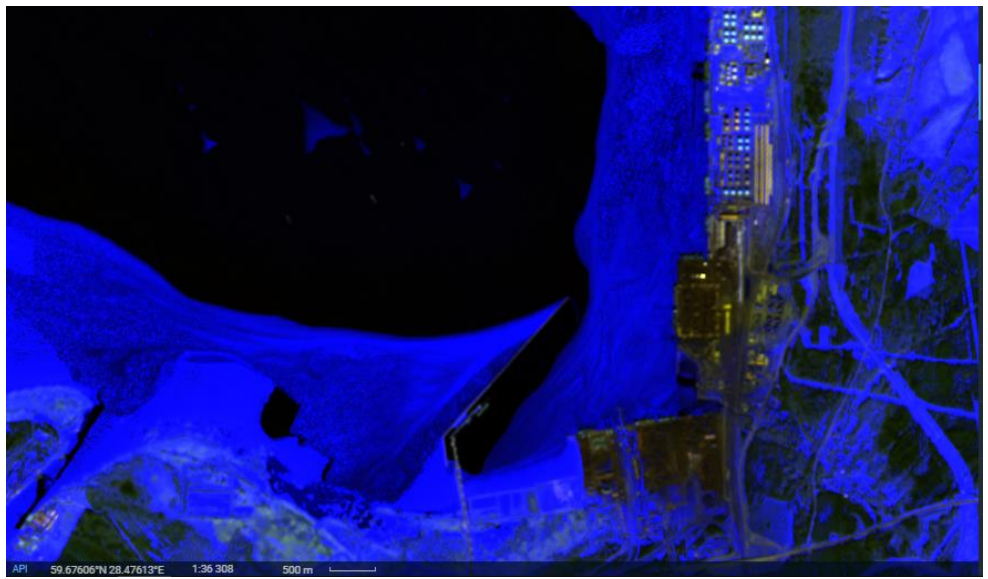

Fig.2. Ice field in the vicinity of the port of Ust-Luga on 22/03/2021, visualized with EOS using LV False Color (Urban) Application, scale $500 \mathrm{~m}$.

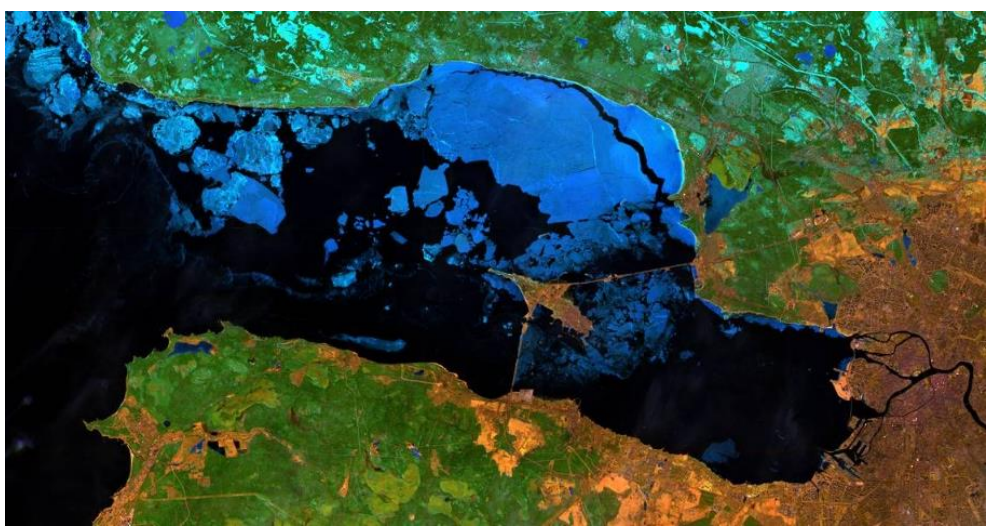

Fig.3. Ice field near the port of Saint Petersburg 07/04/2019, visualized using LV Agriculture Application, scale $5 \mathrm{~km}$.

As the main result, we propose to use the above-mentioned GIDOPs as the basis for a low-cost GISS and MSS for SDMA, especially in the Arctic and Subarctic. Note, decoding and discussing the data from figures 1-3 is not the task of this article.

\section{Discussion}

Above proposed low-cost innovative digital tools for SDMA can be used in educational and training purposes [2]. The essential task of university practical learning in the field of SDMA will be to teach students the practical aspects of work with GISS tools, which requires a develop d learning base within special geo-information systems (GIS) laboratory. In some cases, real practical work in special GIS laboratory can be undergoes with virtual reality (VR) technologies, that can reduce total cost of learning process.

\section{Conclusions}

Paper discusses innovative digital tools development for SDMA, especially in Arctic and Subarctic, which simultaneously takes into account the impact of the period of Industry 4.0, climate change and the COVID-19 pandemic. In research, there was used Foresight 
technologies, theory of decision making under uncertainties, risk management approach, methods of data bases constructing, web-technologies and virtual reality tools. As study result, authors suggest to use GODOPs VesselFinder and EOS, including its Land Viewer (LV) product, as the main digital tools within GISS and MSS for SDMA, especially in Arctic and Subarctic. Research results can be recommended to use in educational and training purposes, including preparing Master's programs in environment economics, Earth sciences and others areas. The presented research results have significant scientific novelty can be useful for private investors, independent market players, government and municipal organizations. In article, all graphical materials are original and produced by authors with data from open sources.

\section{Acknowledgements}

Digital platform https://www.researchgate.net/profile/Valery_Abramov2/ gave excellent opportunities to preliminary discussion and data exchange while this research.

\section{References}

1. M. Shilin, I. Sikarev, E. Baikov, G. Gogoberidze, O. Petrieva, E3S Web Conf., 258, 01003 (2021)

2. S. Lukyanov, N. Popov, I. Sikarev, E. Rumyantseva, O. Petrieva, E3S Web Conf., 258, 01004 (2021)

3. G. Gogoberidze, J. Lednova, A. Chusov, M. Shilin, 2018 IEEE/OES Baltic International Symposium, BALTIC 2018, 8634848 (2019)

4. E. P. Istomin, V. G. Burlov, V. M. Abramov, A. G. Sokolov, S. I. Bidenko, SGEM, 19(5.3), 139 (2019)

5. V. A. Bolshakov, T. V. Vekshina, V. M. Abramov, V. N. Veretennikov, E. M. Korinets, SGEM, 19(2.1), 903 (2019)

6. M. Shilin, V. Abramov, A. Chusov, Transportation Research Procedia, 54, 654 (2021)

7. E.S., Andreeva, M.B., Shilin, V.M., Abramov, S.S., Andreev, E.A. Yaily, SGEM, 19(5.1), 399 (2019)

8. O. N. Mandryka, V. M. Abramov, M. B. Shilin, A. A. r. Ershova, Y. L. Matveev, A. N. Chusov, N. N. Popov, IBIMA 2019: Education Excellence and Innovation Management through Vision 2020, 7173 (2019)

9. A. Ershova, Ya. Matveev, M. Shilin, N. Popov, O. Mandryka, A. Chusov, E3S Web of Conferences, 110, 0102 (2019)

10. A. Ershova, M. Shilin, V. Abramov, O. Mandryka, A. Chusov, SGEM, 19(5.2), 347 (2019)

11. J. Lednova, A. Chusov, M. Shilin, 2012 IEEE/OES Baltic International Symposium, BALTIC 2012, 6249169 (2012)

12. J. Lednova, G. Gogoberidze, V. Zhigulsky, M. Shilin, A. Chusov, MEDCOAST 2019, 1, 161 (2019)

13. J. Lednova, A. Chusov, M. Shilin, EMECS 2013 - MEDCOAST 2013 Joint Conference, 2, 1024 (2013)

14. E. P. Istomin, V. M. Abramov, O. M. Lepeshkin, E. A. Baikov, S. I. Bidenko, SGEM, 19, 953 (2019) 
15. A. Sokolov, V. Abramov, E. Istomin, E. Korinets, V. Bolshakov, T. Vekshina, IOP Conference Series: Materials Science and Engineering, 940(1), 012003 (2020)

16. S. V. Lukyanov, V. M. Abramov, A. S. Averkiev, A. E. Rybalko, Yu. A. Tatarenko, N. S. Frolova, O. I. Shevchuk, IBIMA 2019: Education Excellence and Innovation Management through Vision 2020, 7112 (2019)

17. L. N. Karlin, V. M. Abramov, A. A. Ovsiannikov, Oceanology, 49(3), 327 (2009)

18. A. Ershova, M. Shilin, V. Zhigulsky, A. Chusov, V. Abramov, T. Bagrova, N. Popov, 2018 IEEE/OES Baltic International Symposium, BALTIC 2018, 8634858 (2018)

19. M. P. Fedorov, M. B. Shilin, Power Technology and Engineering, 44(2), 117 (2010)

20. V. G. Burlov, V. M. Abramov, T. M. Tatarnikova, IOP Conference Series: Earth and Environmental Science, 666(5), 052076 (2021)

21. T. Eremina, A. Ershova, G. Martin, M. Shilin, 2018 IEEE/OES Baltic International Symposium, BALTIC 2018, 8634860 (2019)

22. N. Bobylev, A. Chusov, M. Shilin, G. Gogoberidze, A. Ershova, J. Lednova, E3S Web of Conferences, 164, 01010 (2020)

23. Y. S. Vasil'ev, V. I. Maslikov, M. B. Shilin, A. N. Chusov, D. V Molodtsov, T. R. Eremina, A. A. Ershova, Power Technology and Engineering, 53(3), 314 (2019)

24. S. Kouzov, M. Shilin, A. Chusov, J. Lednova, IEEE/OES Baltic International Symposium 2014, BALTIC 2014, 6887863 (2014)

25. V. Mikheev, M. Shilin, V. Abramov, V. Zhigulsky, A. Chusov, SGEM, 19(5.2), 701 (2019)

26. S. Kouzov, A. Chusov, J. Lednova, V. Zhigulsky, M. Shilin, A. Ershova, MEDCOAST 2017, 1, 257 (2017)

27. G. Gogoberidze, V. Zhigulsky, M. Shilin, A. Ershova, A. Chusov, SGEM, 17(52), 935 (2017)

28. E. P. Istomin, A. G. Sokolov, V. M. Abramov, V. V. Novikov, E. A. Yaily, SGEM, 19(2.1), 753 (2019)

29. N. Popov, E. Istomin, A. Popova, V. Abramov, A. Sokolov, A. Levina, IBIMA 2019: Education Excellence and Innovation Management through Vision 2020 2019, 8575

30. A. Sokolov, A. Fokicheva, V. Abramov, E. Istomin, E. Goloskvskaya, A. Levina, IBIMA 2019: Education Excellence and Innovation Management through Vision 2020, 8638 (2019) 